\title{
Unsatisfactory risk factor control and high rate of new cardiovascular events in patients with myocardial infarction and prior coronary artery disease
}

Jarle Jortveit ${ }^{*}$ (D), Sigrun Halvorsen², Anete Kaldal ${ }^{1}$, Are Hugo Pripp ${ }^{3}$, Ragna Elise S. Govatsmark ${ }^{4}$ and Jørund Langørgen ${ }^{5}$

\begin{abstract}
Background: Patients with established coronary artery disease (CAD) have an increased risk of new cardiovascular events. An underuse of secondary preventive drugs has been observed, and many patients may not attain the treatment goals for secondary prevention. The aims of the present nationwide register-based cohort study were to assess the degree of risk factor control and long-term outcomes in patients $<80$ years with Type 1 myocardial infarction (MI) with and without prior CAD.

Methods: Data concerning all patients with Ml admitted to hospitals in Norway from 2013 to 2016 were retrieved from the Norwegian Myocardial Infarction Register (NORMI). Long-term mortality was obtained through linkage with the Norwegian Cause of Death Registry.

Results: In total, 47,204 patients were registered in the NORMI from 2013 to 2016. Prior CAD was recorded in 7219 (25.2\%) of the 28,607 patients $<80$ years old with Type 1 Mls. On average, 3 of the 6 defined treatment targets for secondary preventive therapy were attained, and only $1 \%$ of the patients achieved all targets. Patients with MI and prior CAD had increased risk of death or new Ml compared to patients without prior CAD during long-term followup (adjusted HR 1.6, 95\% Cl 1.5-1.7).
\end{abstract}

Conclusions: Prior CAD was frequent in patients with acute MI. The attainment of secondary preventive treatment targets in patients with $\mathrm{Ml}$ and prior CAD was not optimal, and the long-term outcomes were reduced compared to patients without prior CAD. Increased efforts to improve risk factor control are needed.

Keywords: Secondary prevention, Myocardial infarction, Risk factors

\section{Background}

Ischaemic heart disease remains a frequent cause of mortality and morbidity in Europe [1]. Patients with established coronary artery disease (CAD), defined as prior myocardial infarction (MI), percutaneous coronary intervention (PCI) or coronary artery bypass grafting (CABG), have a high risk of new cardiovascular events or death [2]. All patients with diagnosed CAD should be given advises regarding therapeutic lifestyle changes,

\footnotetext{
* Correspondence: jarle.jortveit@sshf.no

${ }^{1}$ Department of Cardiology, Sørlandet Hospital, Box 783, Stoa, 4809 Arendal, Norway

Full list of author information is available at the end of the article
}

including physical activity, dietary modification/weight loss, and smoking cessation, and administered adjunctive drug therapies of proven benefit in reducing the risk of new events [3-8]. Despite extensive documentation and recommendations in international guidelines, an underuse of secondary preventive drugs has been observed following MI [9]. The EUROpean Action on Secondary and Primary prevention by Intervention to Reduce Events (EUROASPIRE), the REduction of Atherothrombosis for Continued Health (REACH) and the prospeCtive observational LongitudinAl RegIstry oF patients with stable coronary arterY disease (CLARIFY) demonstrated that many patients with CAD did not attain the treatment

(c) The Author(s). 2019 Open Access This article is distributed under the terms of the Creative Commons Attribution 4.0 International License (http://creativecommons.org/licenses/by/4.0/), which permits unrestricted use, distribution, and reproduction in any medium, provided you give appropriate credit to the original author(s) and the source, provide a link to the Creative Commons license, and indicate if changes were made. The Creative Commons Public Domain Dedication waiver (http://creativecommons.org/publicdomain/zero/1.0/) applies to the data made available in this article, unless otherwise stated. 
goals for secondary prevention [10-13]. Similar findings have also been reported by local hospitals in Norway and from other European countries [14, 15]. In previous studies, the risk of selection bias and low response rates were matters of concern and limited the validity of the findings. In Norway, national health registers with mandatory registration by law and almost complete follow-up provide an opportunity to study a nationwide and unselected patient population.

The aims of the present study were to investigate the degree of risk factor control in a nationwide cohort of all patients admitted to hospitals in Norway with acute $\mathrm{MI}$ and prior CAD, and to study long-term outcomes in these patients compared to patients with acute MI but without prior $\mathrm{CAD}$.

\section{Methods}

\section{Study population}

All patients $<80$ years admitted to Norwegian hospitals with Type 1 MI from 1 January 2013, to 31 December 2016, and registered in the Norwegian Myocardial Infarction Register (NORMI) were included in this study. Registration in this registry is mandatory (the Norwegian Cardiovascular Disease Registry Regulation and the Norwegian Health Register Act), and consent by the patient is not required. The registry contains information on gender, age, known risk factors, previous illness and medication, symptoms and clinical findings on admission, in-hospital assessment, therapy and complications, drugs prescribed at discharge, and time of death. The registration and quality of the information in NORMI have been described previously [16-18]. The index MI was defined as the first Type $1 \mathrm{MI}$ in the study period.

\section{Definitions}

\section{Myocardial infarction}

The NORMI adhered to the third universal definition of myocardial infarction in the study period [19]. Troponin was the preferred biochemical marker of MI. A diagnostic cut point of $\geq 30 \mathrm{ng} / \mathrm{l}$ for troponin $\mathrm{T}$ was used up to May 2013. After 1 June 2013, the diagnostic limit of troponin $\mathrm{T}>14 \mathrm{ng} / \mathrm{l}$ was recommended. The reference limits (99th percentile) for troponin I were dependent on the manufacturer. All MIs were classified as ST-elevation MI (STEMI) or non-ST-elevation MI (nSTEMI) on the basis of the diagnostic ECG [19].

\section{Secondary preventive treatment targets}

In accordance with the European Society of Cardiology guidelines, the following secondary preventive treatment targets were defined: $[3,4,7,8]$.

- Daily use of acetylsalicylic acid

- Daily use of statins
- No smoking

- Blood pressure $<140 / 90 \mathrm{mmHg}$

- LDL cholesterol $<1.8 \mathrm{mmol} / \mathrm{L}$

- Body mass index $(\mathrm{BMI})<25 \mathrm{~kg} / \mathrm{m}^{2}$

- HbA1c $\leq 7.0 \%$ in patients with diabetes

\section{Outcomes and follow-up}

The primary endpoint was a composite of all-cause mortality or new MI during follow-up. The secondary endpoint was all-cause mortality during follow-up. The NORMI were linked to the Norwegian Cause of Death Registry to obtain the number of deaths and death dates. New MIs were obtained from the NORMI. Follow-up with respect to new MIs was complete until 31 December 2016, and until 31 December 2017, with respect to death.

\section{Statistical analysis}

Continuous variables are presented as the mean \pm SD (standard deviation) or median (25th percentile, 75th percentile), and differences between groups were analysed

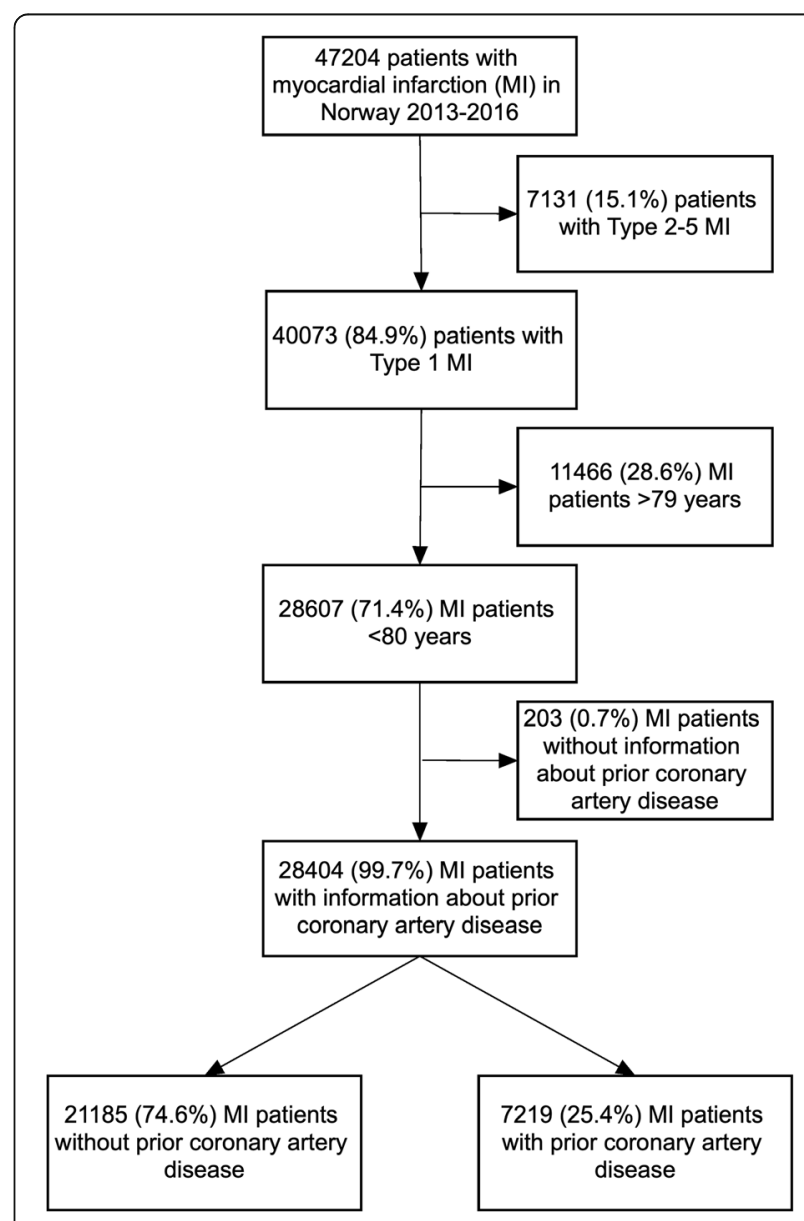

Fig. 1 Patients admitted to hospitals in Norway with myocardial infarction from 2013 to 2016 
Table 1 Clinical characteristics of patients < 80 years with Type 1 myocardial infarction, Norway 2013-2016 $(n=28,404)$

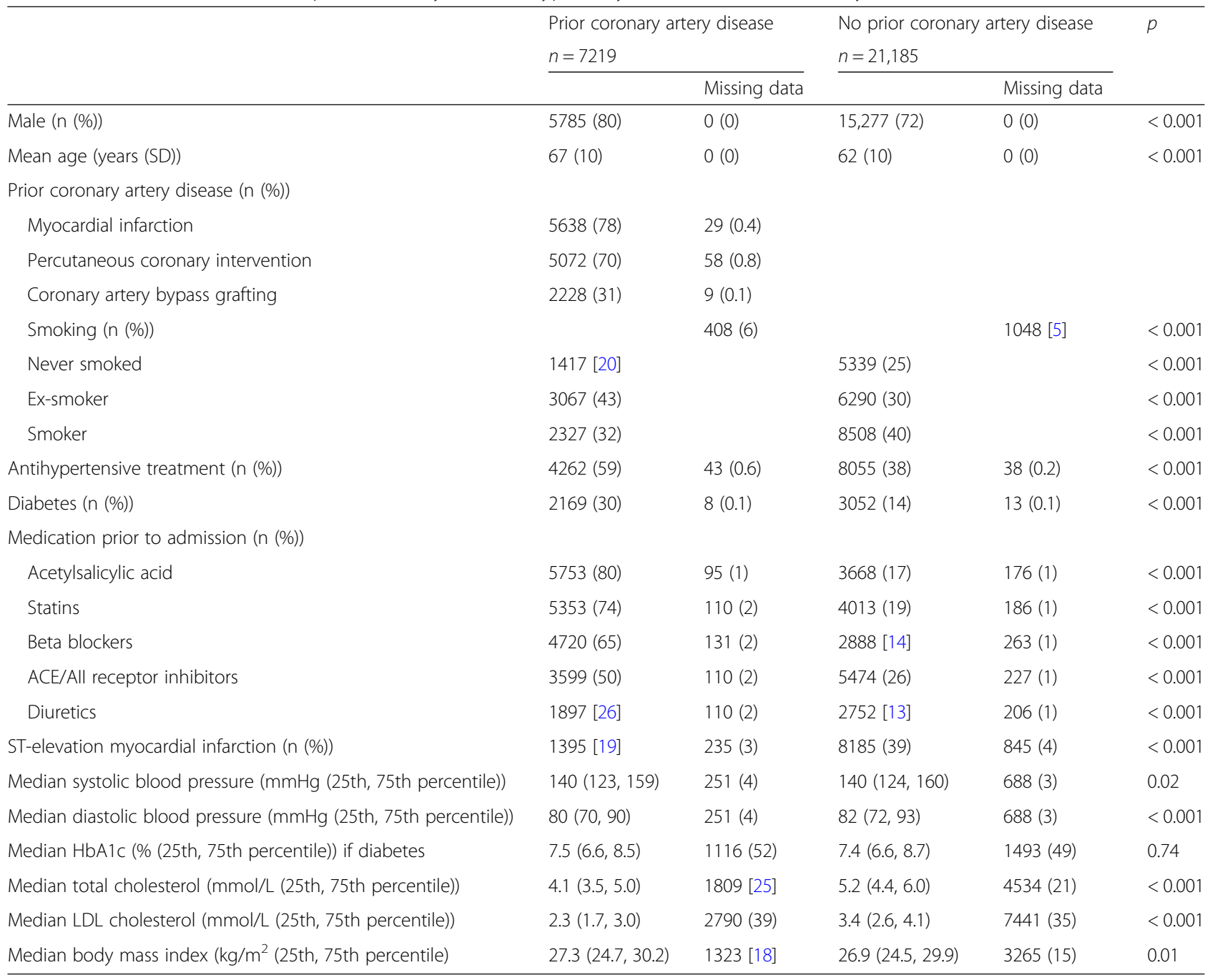

Table 2 Treatment of patients < 80 years with Type 1 myocardial infarction $(n=28,404)$, Norway 2013-2016

\begin{tabular}{|c|c|c|c|c|c|c|}
\hline & \multicolumn{2}{|c|}{$\begin{array}{l}\text { Prior coronary artery disease } \\
n=7219\end{array}$} & \multicolumn{2}{|c|}{$\begin{array}{l}\text { No prior coronary artery disease } \\
n=21,185\end{array}$} & \multirow[b]{3}{*}{$\begin{array}{l}\text { Odds ratio } \\
(95 \% \mathrm{Cl}, p)^{1)}\end{array}$} & \multirow[b]{3}{*}{$\begin{array}{l}\text { Age- and gender-adjusted odds ratio } \\
(95 \% \mathrm{Cl}, p)^{1)}\end{array}$} \\
\hline & \multirow[b]{2}{*}{ n (\%) } & \multirow{2}{*}{$\begin{array}{l}\text { Missing data } \\
\mathrm{n}(\%)\end{array}$} & \multirow[b]{2}{*}{ n (\%) } & \multirow{2}{*}{$\begin{array}{l}\text { Missing data } \\
\text { n (\%) }\end{array}$} & & \\
\hline & & & & & & \\
\hline Coronary angiogram & $5951(82)$ & $2(0)$ & $18,873(89)$ & $0(0)$ & $\begin{array}{l}0.6(0.5-0.6,< \\
0.001)\end{array}$ & $0.6(0.6-0.7<0.001)$ \\
\hline $\begin{array}{l}\text { Percutaneous coronary } \\
\text { intervention (PCI) }\end{array}$ & $4179(58)$ & $0(0)$ & $15,178(72)$ & $1(0)$ & $\begin{array}{l}0.6(0.6-0.7,< \\
0.001)\end{array}$ & $0.6(0.6-0.7,<0.001)$ \\
\hline \multicolumn{7}{|c|}{ Medication at discharge (discharged alive, $n=27,442$ ) } \\
\hline Acetylsalicylic acid & $6682(96)$ & $5(0)$ & $19,907(97)$ & $20(0)$ & $\begin{array}{l}0.8(0.7-0.9,< \\
0.001)\end{array}$ & $0.9(0.7-1.0,0.03)$ \\
\hline $\begin{array}{l}\text { Dual antiplatelet therapy } \\
\text { (DAPT) }\end{array}$ & $5949(86)$ & $12(0)$ & $18,228(89)$ & $32(0)$ & $\begin{array}{l}0.8(0.7-0.8,< \\
0.001)\end{array}$ & $0.9(0.8-0.9,0.001)$ \\
\hline Statins & $6348(92)$ & $7(0)$ & $18,985(93)$ & $26(0)$ & $\begin{array}{l}0.9(0.8-0.9 \\
0.003)\end{array}$ & $0.9(0.8-1.0,0.06)$ \\
\hline
\end{tabular}

\footnotetext{
${ }^{1)}$ Reference: No prior coronary artery disease
} 
using independent sample $\mathrm{T}$ tests or Mann-Whitney non-parametric tests or, as appropriate. Categorical variables are presented as numbers and percentages, and differences between groups were analysed by the chi-squared test. Odds ratios (OR) were calculated by logistic regression and were age- and gender-adjusted. Kaplan-Meier curves for event-free survival were estimated and Cox regression analyses were used to calculate hazard ratios (HRs) with 95\% confidence intervals (CIs) for death and/ or new MI. The following covariates were included in the multivariate analyses: age, gender, smoking, history of heart failure, diabetes, hypertension, renal failure, coronary angiogram and relevant medication (acetylic acid, dual antiplatelet therapy and statins). A $p$-value of $<0.05$ was regarded as statistically significant. The data were analysed using the programme STATA, version 15 (StataCorp LLC, College Station, TX, USA).

\section{Ethics}

The Regional Committee for Medical and Health Research Ethics approved the study (REK 2016/170).

\section{Results}

During the period 2013-2016, 47,204 patients were registered in the NORMI. Of these, 28,607 were $<80$ years old and diagnosed with Type 1 MI (Fig. 1). A history of CAD was recorded in 7219 (25.2\%) patients. The clinical characteristics at the time of the index MI in patients with and without prior CAD are presented in Table 1. Previous MI was the most frequent type of prior CAD. Patients with prior CAD were older and more likely to have hypertension and diabetes compared to patients without prior CAD. They were also more likely to have quit smoking.

Patients with MIs and prior CAD were less likely to undergo coronary angiography and PCI and less likely to be prescribed secondary preventive therapy at their discharge from hospital compared to patients with no prior CAD (Table 2).

The attainment of secondary preventive treatment goals in patients $<80$ years with prior CAD is shown in Fig. 2. The risk factor control was low. About one out of five did not use acetylsalicylic acid and statins. One out of three smoked despite prior CAD. Only $43 \%$ of patients had satisfactory blood pressure control. Unfortunately, the NORMI did not have complete coverage with respect to BMI, LDL cholesterol and HbA1c. In patients with recorded information, the percentage achieving treatment targets was $27 \%$ for BMI (1611 of 5896 patients), 25\% for LDL

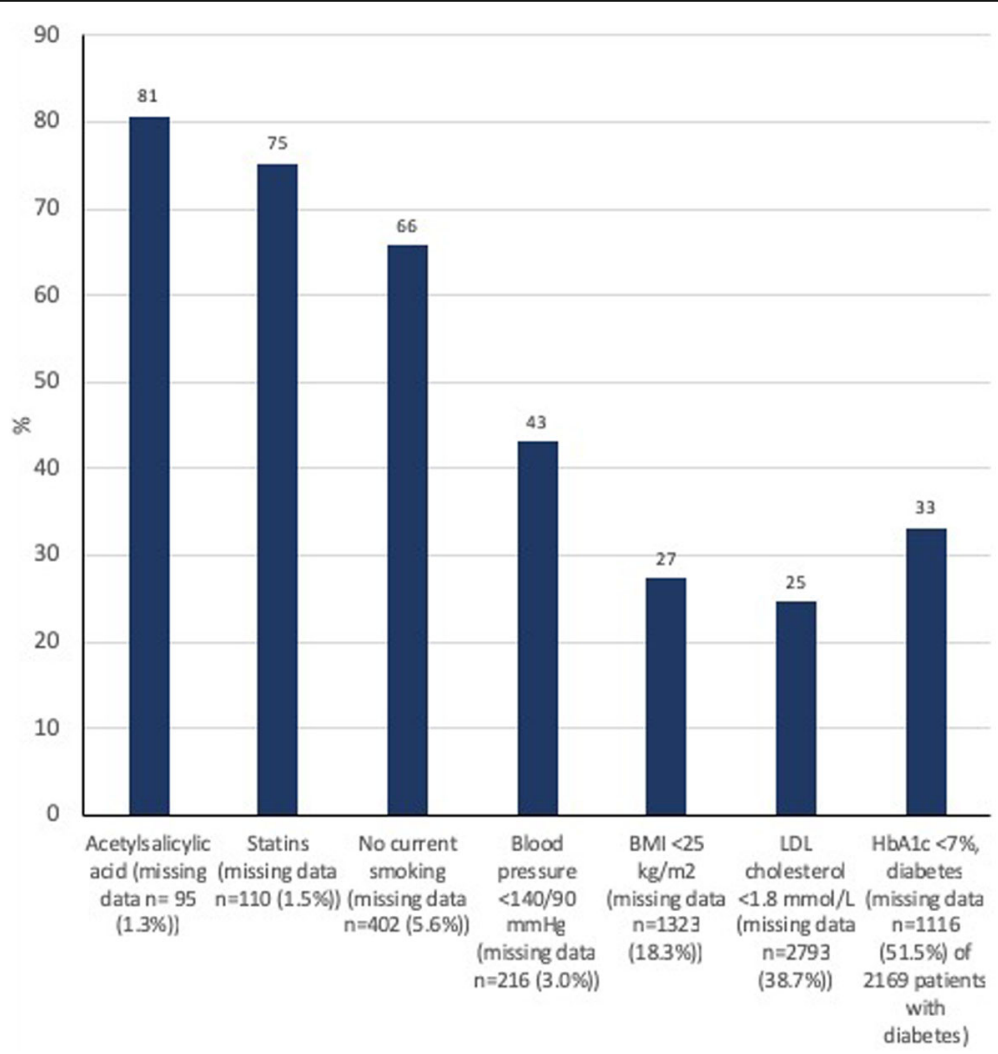

Fig. 2 Risk factor control in patients < 80 years with coronary artery disease hospitalized with Type 1 myocardial infarction in Norway from 2013 to $2016(n=7219)$ (Patients with missing data were excluded) 
cholesterol (1092 of 4426 patients), and $33 \%$ for HbA1c in patients with diabetes (349 of 1053 patients).

The mean number of treatment targets achieved was three (Fig. 3). Only 72 (1.0\%) patients with prior CAD were registered as having achieved all secondary preventive treatment targets at hospital admission. We found no differences in the overall achievement of treatment targets between different age groups (data not shown). Women were less likely to smoke (age-adjusted OR 0.8, 95\% CI 0.7-0.9, $p=0.001$ ) and to be overweight (age-adjusted OR 0.7, 95\% CI 0.6$0.8, p<0.001)$ compared to men. We found no gender differences for the other risk factors, but women used less statins than men (age-adjusted OR 0.8, 95\% CI $0.7-0.9, \mathrm{p}<0.001)$.

In total, $2162(30.0 \%)$ and $3118(14.7 \%)$ patients with and without prior CAD, experienced a new MI and/or death (Median follow-up time: 944 days (25th, 75th percentile: 548,1218$)$ ).

and 1411 (19.6\%) patients with and 2232 (10.5\%) patients without prior CAD died (median follow-up time 1004 days (25th, 75 th percentile: 609,1400$)$ ) during the follow-up time (Fig. 4). The risk of recurrent MI or death during the study period was significantly increased in patients with prior CAD, also after multivariate adjustment (Table 3).

High adherence to secondary preventive treatment was associated with improved outcome. If $\geq 3$ secondary preventive treatment targets were attained, the risk of recurrent MI or death was significantly lower compared to patients with lower degrees of risk factor control (Table 4).

\section{Discussion}

This nationwide study showed that prior CAD was frequent $(25 \%)$ in consecutive patients admitted with acute MI to hospitals in Norway. On average, only half the treatment targets for secondary preventive therapy were attained, and only $1 \%$ of patients with $\mathrm{MI}$ and prior CAD had reached all the targets. The risk of recurrent MI and death during long-term follow-up was significantly increased in patients with prior CAD compared to patients without prior CAD.

There is compelling scientific evidence supporting that a healthier lifestyle and use of cardioprotective medication in patients with established CAD reduce the risk of recurrent cardiovascular events. Smoking cessation after MI reduces coronary mortality by $36 \%$, and the use of statins reduces the five-year incidence of cardiovascular

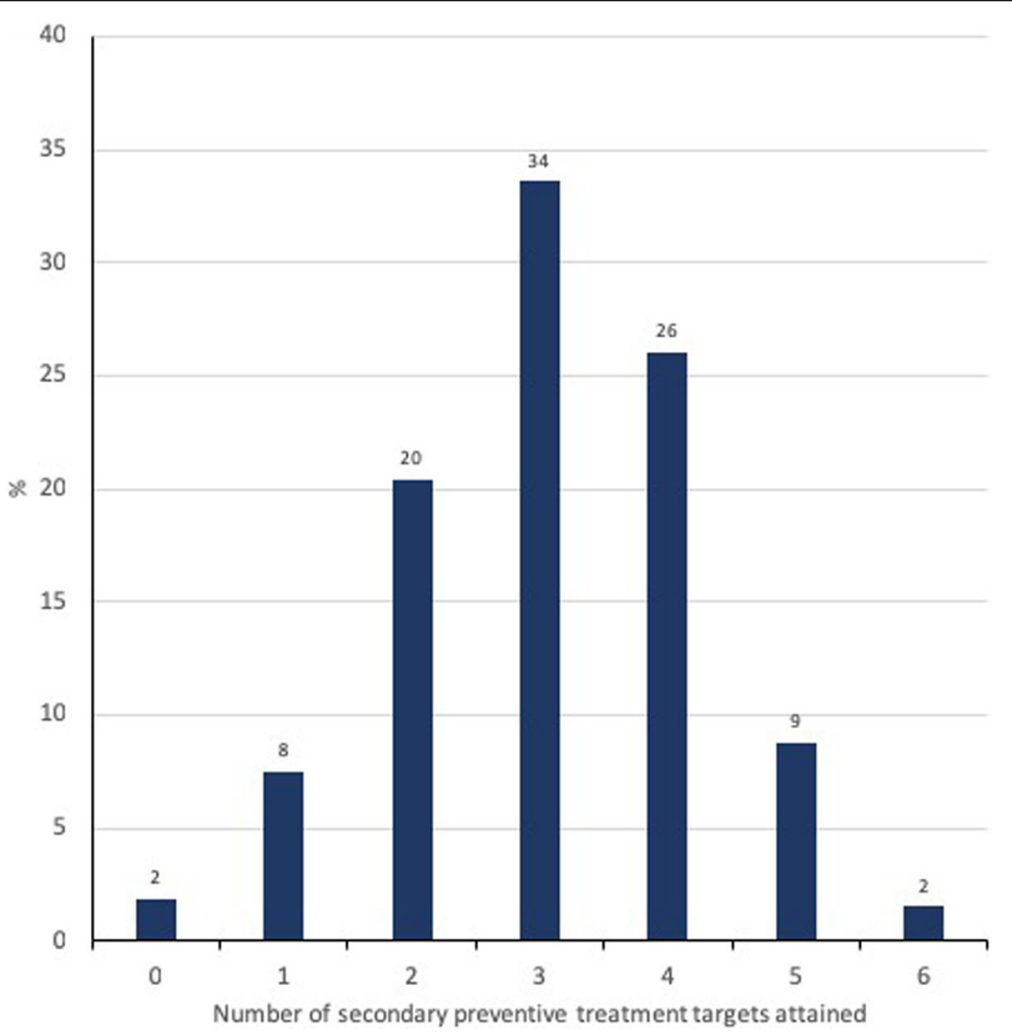

Fig. 3 The numbers of secondary preventive treatment targets* attained in patients $<80$ years hospitalized with Type 1 myocardial infarction and having prior coronary artery disease in Norway from 2013 to $2016(n=7219)$ (No smoking, blood pressure $<149 / 90 \mathrm{mmHg}$, LDL cholesterol < 1.8 $\mathrm{mmol} / \mathrm{L}$, body mass index $<25 \mathrm{~kg} / \mathrm{m}^{2}$, acetylsalicylic acid and statin use.) (Missing information was counted as "not attained") 

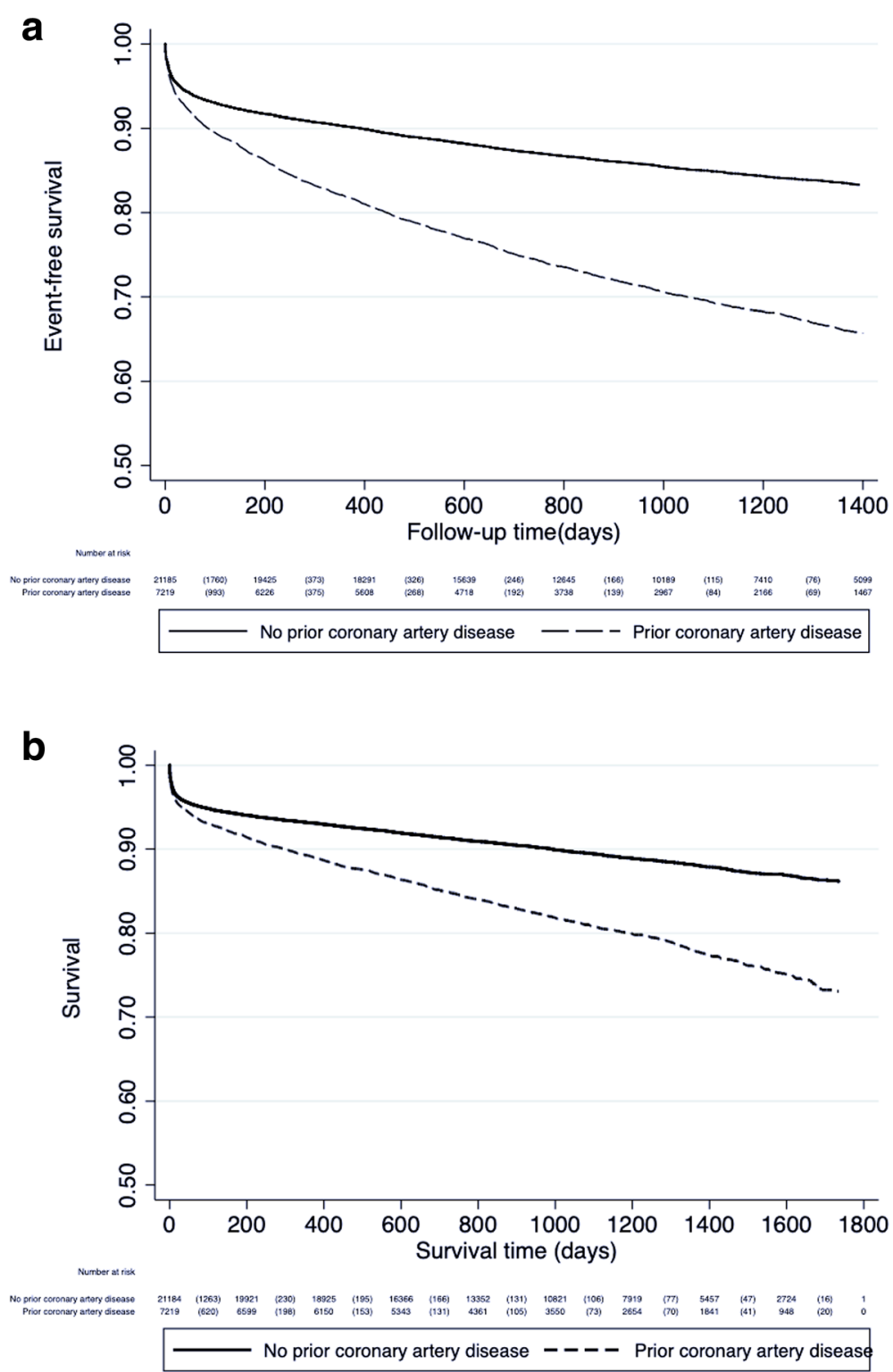

Fig. 4 a Death or recurrent myocardial infarction during long-term follow-up in patients $<80$ years with Type 1 myocardial infarction, with and without prior coronary artery disease in Norway from 2013 to 2016. b Cumulative survival following Type 1 myocardial infarction in patients $<80$ years with and without prior coronary artery disease in Norway from 2013 to 2016

events by approximately $20 \%$ per $\mathrm{mmol} / \mathrm{L}$ of LDL cholesterol reduction [20, 21]. However, EUROASPIRE IV, a cross-sectional survey from selected centres in 24 European countries, concluded that the majority of coronary patients did not achieve the targets for secondary prevention; six months after acute coronary syndrome or revascularization, $16 \%$ of the patients smoked; $38 \%$ were obese; 43 and $81 \%$ had blood pressure and LDL cholesterol above targets, respectively; and $47 \%$ of patients with diabetes did not have their diabetes under control according to the relevant guidelines [13]. Similar findings have been described in other large studies $[12,15$,
$22,23]$. The present nationwide study from Norway also showing moderate adherence to secondary prevention guidelines in patients with prior CAD admitted with acute MIs, are in accordance with these results. Although Norway has a well-functioning health care service with low direct cost for the patients and most patients received guideline-recommended drugs, control of LDL cholesterol, blood pressure and blood glucose were inadequate. Possible explanations may include a lack of up-titration of drug doses, lack of drug combinations with different modes of actions, and poor patient drug compliance. Another reason might be the lack of a 
Table 3 Long-term outcomes in patients < 80 years hospitalized with Type 1 myocardial infarction, Norway 2013-2016

\begin{tabular}{|c|c|c|c|c|c|c|}
\hline & \multirow{3}{*}{$\begin{array}{l}\text { Prior coronary artery } \\
\text { disease } \\
n=7219 \\
n(\%)\end{array}$} & \multirow{3}{*}{$\begin{array}{l}\text { No prior coronary } \\
\text { artery disease } \\
n=21,185 \\
n(\%)\end{array}$} & \multirow[b]{3}{*}{$\begin{array}{l}\text { Unadjusted HR } \\
(95 \% \mathrm{Cl}, p)^{1)}\end{array}$} & \multirow[b]{3}{*}{$\begin{array}{l}\text { Age- and gender } \\
\text { adjusted HR } \\
(95 \% \mathrm{Cl}, p)^{1)} \\
\end{array}$} & \multirow[b]{3}{*}{$\begin{array}{l}\text { Multivariate adjusted } \\
\mathrm{HR}-\text { model } 1^{4)} \\
(95 \% \mathrm{Cl}, p)^{1)}\end{array}$} & \multirow[b]{3}{*}{$\begin{array}{l}\text { Multivariate adjusted } \\
\text { HR - model } 2^{5)} \\
(95 \% \mathrm{Cl}, p)^{1)} \\
\end{array}$} \\
\hline & & & & & & \\
\hline & & & & & & \\
\hline $\begin{array}{l}\text { Myocardial infarction } \\
\text { or death }{ }^{2)}\end{array}$ & $2162(30.0)$ & $3118(14.7)$ & $2.2(2.1-2.3,<0.001)$ & $\begin{array}{l}1.8(1.7-1.9,< \\
0.001)\end{array}$ & $1.7(1.6-1.7,<0.001)$ & $1.6(1.5-1.7,<0.001)$ \\
\hline Death $^{3)}$ & $1411(19.6)$ & $2232(10.5)$ & $1.9(1.8-2.0,<0.001)$ & $\begin{array}{l}1.5(1.4-1.6,< \\
0.001)\end{array}$ & $1.3(1.2-1.4,<0.001)$ & $1.3(1.2-1.4,<0.001)$ \\
\hline
\end{tabular}

1) Reference: No prior coronary artery disease

2) Median follow-up time: 944 days (25th, 75 th percentile: 548,1218 )

3) Median follow-up time 1004 days (25th, 75 th percentile: 609, 1400)

4) Age, gender, diabetes, smoking, hypertension, heart failure and renal failure

5) Age, gender, diabetes, smoking, hypertension, heart failure, renal failure, coronary angiogram and medication at discharge (acetylic acid, dual antiplatelet therapy and statins)

national programme for systematic outpatient secondary prevention follow-up. Such programmes are clearly associated with a reduction in all-cause and cardiac mortality and recurrent cardiovascular events [24]. Less than half the patients included in EUROASPIRE IV accessed a cardiac disease prevention programme $[13,25,26]$. In Norway, there are large differences between hospitals with respect to treatment, prevention programmes and degree of follow-up [27]. Unfortunately, the NORMI does not register information about patients after the primary hospital stay.

Improved survival after MI have been reported in many European countries over the last decades [1]. However, this study demonstrated a high rate of subsequent cardiovascular events after MI in patients with prior CAD. Similar findings have recently been reported from Sweden [2]. These Scandinavian studies both included nationwide populations and had minimal selections bias. Prior CAD was demonstrated to be an independent risk factor for new ischaemic events and death in patients with acute MI [2]. In our opinion, the adverse outcome after $\mathrm{MI}$ in patients with prior CAD may partly be explained by the unsatisfactory risk factor control and less invasive therapy of the index MI in patients with prior CAD. The reasons for fewer patients with prior $\mathrm{CAD}$ undergoing coronary angiograms and PCI than patients with MI without prior CAD are not clear, but a higher incidence of comorbidities and, consequently, a greater risk of complications, may have been an important factor.

The main strengths of this study are the large and unselected population comprising nearly all patients hospitalized with MI in Norway from 2013 to 2016 and nearly complete follow-up with respect to new MIs and/or death. However, there are some important limitations. This study was an observational study, making it impossible to demonstrate causal associations between prior CAD and long-term outcomes or between the degree of adherence to secondary preventive guidelines and outcomes. Only MIs that led to hospitalization were registered in the NORMI. A few hospitals did not deliver complete data for the whole period, the NORMI did not have complete coverage for all variables e.g. BMI, LDL cholesterol and HbA1c, and the recorded blood pressures were not obtained in a standardized setting. Data on patients transferred between hospitals were merged

Table 4 Risk of recurrent myocardial infarction or death according to attainment of preventive treatment targets in patients $<80$ years with Type 1 myocardial infarction and prior coronary artery disease, Norway 2013-2016

\begin{tabular}{|c|c|c|c|c|c|}
\hline & \multirow{3}{*}{$\begin{array}{l}0-2 \text { preventive treatment } \\
\text { targets attained } \\
n=2220 \\
n(\%)\end{array}$} & \multirow{3}{*}{$\begin{array}{l}\text { 3-6 preventive treatment } \\
\text { targets attained } \\
n=4999 \\
n(\%)\end{array}$} & \multirow[b]{3}{*}{$\begin{array}{l}\text { Unadjusted HR } \\
(95 \% \mathrm{Cl}, p)^{1)}\end{array}$} & \multirow[b]{3}{*}{$\begin{array}{l}\text { Age- and gender adjusted } \\
\text { HR }(95 \% \mathrm{Cl}, p)^{1)}\end{array}$} & \multirow[b]{3}{*}{$\begin{array}{l}\text { Multivariate adjusted HR } \\
\left.(95 \% \mathrm{Cl}, p)^{1)}, 4\right)\end{array}$} \\
\hline & & & & & \\
\hline & & & & & \\
\hline $\begin{array}{l}\text { Myocardial infarction or } \\
\text { death }^{2}\end{array}$ & $682(30.7)$ & 1480 (29.6) & $\begin{array}{l}0.9(0.9-1.0 \\
0,19)\end{array}$ & $0.9(0.8-1.0,0,02)$ & $0.9(0.8-1.0,0,05)$ \\
\hline Death $^{3)}$ & $473(21.3)$ & $938(18.8)$ & $\begin{array}{l}0.9(0.8-1.0 \\
0,005)\end{array}$ & $0.8(0.7-0.9,<0,001)$ & $0.8(0.7-0.9,<0,001)$ \\
\hline
\end{tabular}

\footnotetext{
${ }^{1)}$ Reference: $0-2$ preventive treatment targets attained

2) Median follow-up time: 837 days (25th, 75th percentile: 449, 1187)

3) Median follow-up time 974 days (25th, 75 th percentile: 578,1400 )

4) Age, gender, heart failure, renal failure and coronary angiogram
} 
in the register. This led to some uncertainty, particularly in cases of missing or different registration of the same variable. Nevertheless, the coverage of NORMI compared to the Norwegian Patient Register was good and the degree of completeness and correctness of most variables was high $[16,18]$. The NORMI did not register information about patients after the primary hospital stay, and we had no information regarding cardiac rehabilitation programs and causes of death in patients who died.

\section{Conclusions}

One quarter of patients admitted to hospitals in Norway with acute MI had prior CAD. In those patients, the risk factor control was not optimal, and the rates of recurrent MI and death were significantly higher than in patients without prior CAD. In our opinion, a new approach to secondary prevention is needed; all patients with CAD capable of participating in a systematic preventive cardiology programme, should be offered this in order to improve risk factor control.

\section{Abbreviations}

BMI: Body mass index; CABG: Coronary artery bypass grafting; CAD: Coronary artery disease; DAPT: Dual antiplatelet therapy; MI: Myocardial infarction; NORMI: Norwegian myocardial infarction register; PCI : Percutaneous coronary intervention

\section{Acknowledgements}

Not applicable.

\section{Funding}

This work was supported by the South-Eastern Norway Regional Health Authority, Hamar, Norway and the Sørlandet Hospital HF, Arendal, Norway. The funders had no role in the design and conduct of the study; the collection, analysis, and interpretation of the data; or in the preparation, review, and approval of the manuscript

\section{Availability of data and materials}

The data that support the findings of this study are available from the Norwegian Institute of Public health, but restrictions apply to the availability of these data, which were used under license for the current study and so are not publicly available.

\section{Authors' contributions \\ $\mathrm{JJ}$ and $\mathrm{SH}$ were responsible for the conception of the study, the analysis and interpretation of data and they also drafted the manuscript. AHP contributed to the analysis and interpretation of the data and critically revised the manuscript. AK, RESG and JL critically revised the manuscript. All gave final approval and agree to be accountable for all aspects of work ensuring its} integrity and accuracy.

\section{Ethics approval and consent to participate}

The Regional Committee for Medical and Health Research Ethics approved the study (REK 2016/170). No consent to participate was required.

\section{Consent for publication}

Not applicable.

\section{Competing interests}

The authors declare that they have no competing interests.

\section{Publisher's Note}

Springer Nature remains neutral with regard to jurisdictional claims in published maps and institutional affiliations.

\section{Author details}

'Department of Cardiology, Sørlandet Hospital, Box 783, Stoa, 4809 Arendal, Norway. ${ }^{2}$ Department of Cardiology, Oslo University Hospital and University of Oslo, Oslo, Norway. ${ }^{3}$ Oslo Centre of Biostatistics and Epidemiology, Oslo University Hospital, Oslo, Norway. ${ }^{4}$ Department of Medical Quality Registers, St. Olav's Hospital, Trondheim, Norway. ${ }^{5}$ Department of Heart Diseases, Haukeland University Hospital, Bergen, Norway.

Received: 17 November 2018 Accepted: 22 March 2019

Published online: 28 March 2019

\section{References}

1. Townsend N, Nichols M, Scarborough P, Rayner M. Cardiovascular disease in Europe--epidemiological update 2015. Eur Heart J. 2015;36(40):2696-705.

2. Jernberg T, Hasvold P, Henriksson M, Hjelm H, Thuresson M, Janzon M. Cardiovascular risk in post-myocardial infarction patients: nationwide real world data demonstrate the importance of a long-term perspective. Eur Heart J. 2015;36(19):1163-70.

3. Perk J, De Backer G, Gohlke H, Graham I, Reiner Z, Verschuren M, et al. European guidelines on cardiovascular disease prevention in clinical practice (version 2012). The fifth joint task force of the European Society of Cardiology and Other Societies on cardiovascular disease prevention in clinical practice (constituted by representatives of nine societies and by invited experts). Eur Heart J. 2012;33(13):1635-701.

4. Roffi M, Patrono C, Collet JP, Mueller C, Valgimigli M, Andreotti F, et al. 2015 ESC guidelines for the management of acute coronary syndromes in patients presenting without persistent ST-segment elevation: task force for the Management of Acute Coronary Syndromes in patients presenting without persistent ST-segment elevation of the European Society of Cardiology (ESC). Eur Heart J. 2016;37(3):267-315.

5. Eckel RH, Jakicic JM, Ard JD, de Jesus JM, Houston Miller N, Hubbard VS, et al. 2013 AHA/ACC guideline on lifestyle management to reduce cardiovascular risk: a report of the American College of Cardiology/ American Heart Association task force on practice guidelines. Circulation. 2014;129(25 Suppl 2):S76-99.

6. Smith SC Jr, Benjamin EJ, Bonow RO, Braun LT, Creager MA, Franklin BA, et al. AHA/ACCF secondary prevention and risk reduction therapy for patients with coronary and other atherosclerotic vascular disease: 2011 update: a guideline from the American Heart Association and American College of Cardiology Foundation. Circulation. 2011;124(22):2458-73.

7. Piepoli MF, Hoes AW, Agewall S, Albus C, Brotons C, Catapano AL, et al. 2016 European guidelines on cardiovascular disease prevention in clinical practice: the sixth joint task force of the European Society of Cardiology and Other Societies on cardiovascular disease prevention in clinical practice (constituted by representatives of 10 societies and by invited experts)developed with the special contribution of the European Association for Cardiovascular Prevention \& rehabilitation (EACPR). Eur Heart J 2016;37(29):2315-2381.

8. Ibanez B, James S, Agewall S, Antunes MJ, Bucciarelli-Ducci C, Bueno H, et al. 2017 ESC guidelines for the management of acute myocardial infarction in patients presenting with ST-segment elevation: the task force for the management of acute myocardial infarction in patients presenting with STsegment elevation of the European Society of Cardiology (ESC). Eur Heart J. 2018;39(2):119-77.

9. Halvorsen S, Jortveit J, Hasvold P, Thuresson M, Oie E. Initiation of and longterm adherence to secondary preventive drugs after acute myocardial infarction. BMC Cardiovasc Disord. 2016;16:115.

10. Kotseva K, Wood D, De Backer G, De Bacquer D, Pyorala K, Keil U, et al. EUROASPIRE III: a survey on the lifestyle, risk factors and use of cardioprotective drug therapies in coronary patients from 22 European countries. Eur J Cardiovasc Prev Rehabil. 2009;16(2):121-37.

11. Cacoub PP, Zeymer U, Limbourg T, Baumgartner I, Poldermans D, Rother J, et al. Effects of adherence to guidelines for the control of major cardiovascular risk factors on outcomes in the REduction of Atherothrombosis for continued health (REACH) registry Europe. Heart. 2011;97(8):660-7.

12. Ferrari R, Ford I, Greenlaw N, Tardif JC, Tendera M, Abergel H, et al. Geographical variations in the prevalence and management of cardiovascular risk factors in outpatients with CAD: data from the contemporary CLARIFY registry. Eur J Prev Cardiol. 2015;22(8):1056-65. 
13. Kotseva K, Wood D, De Bacquer D, De Backer G, Ryden L, Jennings C, et al. EUROASPIRE IV: a European Society of Cardiology survey on the lifestyle, risk factor and therapeutic management of coronary patients from 24 European countries. Eur J Prev Cardiol. 2016;23(6):636-48.

14. Sverre E, Peersen K, Husebye E, Gjertsen E, Gullestad L, Moum T, et al. Unfavourable risk factor control after coronary events in routine clinical practice. BMC Cardiovasc Disord. 2017;17(1):40.

15. Bebb O, Hall M, Fox KAA, Dondo TB, Timmis A, Bueno H, et al. Performance of hospitals according to the ESC ACCA quality indicators and 30-day mortality for acute myocardial infarction: national cohort study using the United Kingdom myocardial Ischaemia National Audit Project (MINAP) register. Eur Heart J. 2017;38(13):974-82.

16. Jortveit J, Govatsmark RE, Digre TA, Risoe C, Hole T, Mannsverk J, et al. Myocardial infarction in Norway in 2013. Tidsskr Nor Laegeforen. 2014; 134(19):1841-6.

17. Govatsmark RE, Sneeggen S, Karlsaune H, Slordahl SA, Bonaa KH. Interrater reliability of a national acute myocardial infarction register. Clin Epidemiol. 2016;8:305-12

18. Govatsmark RES, Janszky I, Slordahl SA, Ebbing M, Wiseth R, Grenne B, et al. Completeness and correctness of acute myocardial infarction diagnoses in a medical quality register and an administrative health register. Scand J Public Health 2018:1403494818803256.

19. Thygesen $K$, Alpert JS, Jaffe AS, Simoons ML, Chaitman BR, White HD, et al. Third universal definition of myocardial infarction. Eur Heart J. 2012;33(20): 2551-67.

20. Critchley JA, Capewell S. Mortality risk reduction associated with smoking cessation in patients with coronary heart disease: a systematic review. JAMA. 2003;290(1):86-97.

21. Cholesterol Treatment Trialists C, Baigent C, Blackwell L, Emberson J, Holland LE, Reith C, et al. Efficacy and safety of more intensive lowering of LDL cholesterol: a meta-analysis of data from 170,000 participants in 26 randomised trials. Lancet. 2010;376(9753):1670-81.

22. Taylor AJ, Arora NS, Bindeman J, Bhattari S, Feuerstein IM, O'Malley PG. Conventional, emerging, heredity, lifestyle, and psychosocial coronary risk factors: relationships to subclinical atherosclerosis. Prev Cardiol. 2006;9(1):2532.

23. Mendis S, Abegunde D, Yusuf S, Ebrahim S, Shaper G, Ghannem H, et al. WHO study on prevention of REcurrences of myocardial infarction and StrokE (WHO-PREMISE). Bull World Health Organ. 2005;83(11):820-9.

24. Heran BS, Chen JM, Ebrahim S, Moxham T, Oldridge N, Rees K, et al. Exercise-based cardiac rehabilitation for coronary heart disease. Cochrane Database Syst Rev. (2011, 7):CD001800

25. Wood DA, Kotseva K, Connolly S, Jennings C, Mead A, Jones J, et al. Nursecoordinated multidisciplinary, family-based cardiovascular disease prevention programme (EUROACTION) for patients with coronary heart disease and asymptomatic individuals at high risk of cardiovascular disease: a paired, cluster-randomised controlled trial. Lancet. 2008;371(9629):19992012.

26. Giannuzzi P, Temporelli PL, Marchioli R, Maggioni AP, Balestroni G, Ceci V, et al. Global secondary prevention strategies to limit event recurrence after myocardial infarction: results of the GOSPEL study, a multicenter, randomized controlled trial from the Italian cardiac rehabilitation network. Arch Intern Med. 2008;168(20):2194-204.

27. Jortveit J, Halvorsen S. Geographical differences in prescription of secondary preventive drug therapy after acute myocardial infarction in Norway. Eur Heart J Cardiovasc Pharmacother. 2017;3(3):132-3.

\section{Ready to submit your research? Choose BMC and benefit from:}

- fast, convenient online submission

- thorough peer review by experienced researchers in your field

- rapid publication on acceptance

- support for research data, including large and complex data types

- gold Open Access which fosters wider collaboration and increased citations

- maximum visibility for your research: over $100 \mathrm{M}$ website views per year

At $\mathrm{BMC}$, research is always in progress.

Learn more biomedcentral.com/submissions 